\title{
OUTORGA DE DIREITO DE USO DE RECURSO HÍDRICO COMO INSTRUMENTO QUE PRECEDE O LICENCIAMENTO AMBIENTAL NO ESTADO DO RIO DE JANEIRO
}

\author{
Ana Flavia da Silva ${ }^{1} \&$ Marcelo Torres Costa $^{2}$
}

Resumo - A Gestão de Recurso Hídrico é um dos itens fundamentais no Licenciamento Ambiental onde a Outorga é decisiva como parâmetro para o deferimento da implantação de determinadas atividades potencialmente poluidoras, de acordo com o CONAMA $n^{\circ}$ 237/1997. Acerca do SISNAMA - Sistema Nacional de Meio Ambiente é possível observar, como estudo de caso, que no Estado do Rio de Janeiro ocorreu a unificação de três órgãos ambientais: Instituto Estadual de Floresta - IEF, Fundação Superintendência Estadual de Rios e Lagoas - SERLA e Fundação Estadual de Engenharia do Estado do Rio de Janeiro - FEEMA que por meio da Lei $\mathrm{n}^{\circ}$ 5.101/2007, que originou o INEA, fez com que houvesse a integração da Outorga (que era gerenciada pela SERLA) com o Licenciamento Ambiental (que anteriormente era regulado pela FEEMA). Assim, a unificação visa reduzir etapas e tempo de análise desse tipo de processo administrativo. Além disso, serão apresentados nesse trabalho os grandes avanços na Gestão de Recursos Hídricos através da análise da legislação federal e estadual vigente assim como apresentaremos o instrumento de outorga e a cobrança adotada no Estado do Rio de Janeiro visando o cenário atual.

Palavras-Chave - Outorga; Licenciamento Ambiental; Rio de Janeiro.

\begin{abstract}
The Hydric Resource Management is one of the key items in the Environmental Licensing where Grant is decisive as a parameter for the deferral of the implementation of certain potentially polluting activities, according to CONAMA n 237/1997. About SISNAMA - National Environmental System can be seen as a case study, in the State of Rio de Janeiro was the unification of three environmental bodies: State Institute for Forest - IEF, State Superintendent Foundation of

\footnotetext{
${ }^{1}$ Graduanda em Biologia, Universidade Estadual do Rio de Janeiro - UERJ, Instituto de Biologia Roberto Alcântara Gomes IBRAG. Rio de Janeiro/RJ. (21) 983576580 , faleanasilva@gmail.com;

${ }^{2}$ Geólogo, SUB AKVO Ambiental, Rio de Janeiro/RJ. (21) 996677215, geotorresbr@yahoo.com.br.
} 
Rivers and Lakes - SERLA and State of Rio de Janeiro State Engineering Foundation - FEEMA that by Law $\mathrm{n}^{\circ}$ 5.101/2007, which gave the INEA, made there the integration of Grant (which was managed by SERLA) with the Environmental Licensing (formerly it was regulated by FEEMA). Thus, the unification aims to reduce steps and analysis time of such administrative proceedings. There will also be presented in this work the great advances in the management of water resources through the analysis of existing federal and state laws as well as present the grant instrument and collection adopted in the State of Rio de Janeiro aimed at the current scenario.

Keywords - Grant; Environmental Licensing; Rio de Janeiro.

\section{INTRODUÇÃO}

No Brasil o modelo adotado para gestão de Recurso Hídrico se dá por Bacias Hidrográficas, com base na experiência bem sucedida na França. Com isso tivemos que adaptar um sistema de um Estado unitário francês com uma gestão federativa, estadual e municipal (REGO, 2012).

Apesar da descentralização político-administrativa e a ampliação da participação da sociedade civil organizada, conforme a orientação geral definida pelo texto da Constituição Federal do Brasil de 1988, o modelo de gestão de Recursos Hídricos por bacias hidrográficas adotado no Brasil (Lei Federal $n^{\circ}$ 9.433/1997), em função de sua complexidade, depara-se com conflitos significativos em sua implantação e em seu funcionamento, cabendo ressaltar que ele se encontra em diferentes estágios de implantação nos diferentes estados e bacias hidrográficas.

Dentre esses conflitos, destaca-se as instituições que participam do SERHI - Sistema Estadual de Recursos Hídricos com os múltiplos interesses de cada um com a água dentro da bacia hidrográfica, tendo o Estado o papel de conciliação na base do sistema de gestão.

Dentre os diversos instrumentos de gestão instituídos, os Comitês de Bacia Hidrográfica (CBHs) foram definidos como os órgãos consultivos, deliberativos e normativos encarregados da gestão integrada e descentralizada das águas no território sob sua responsabilidade, por meio da participação dos representantes de entidades dos usuários da água, do Poder Público e da sociedade civil. Em 2003, o Conselho Nacional de Recursos Hídricos (CNRH) instituiu a Divisão Hidrográfica Nacional - DHN como base físico-territorial para fins de planejamento e gestão dos Recursos Hídricos e dividiu o território nacional em 12 Regiões Hidrográficas. Conforme observado na Figura 1 o Estado do Rio de Janeiro situa-se na RH11 - Atlântico Sudeste. 


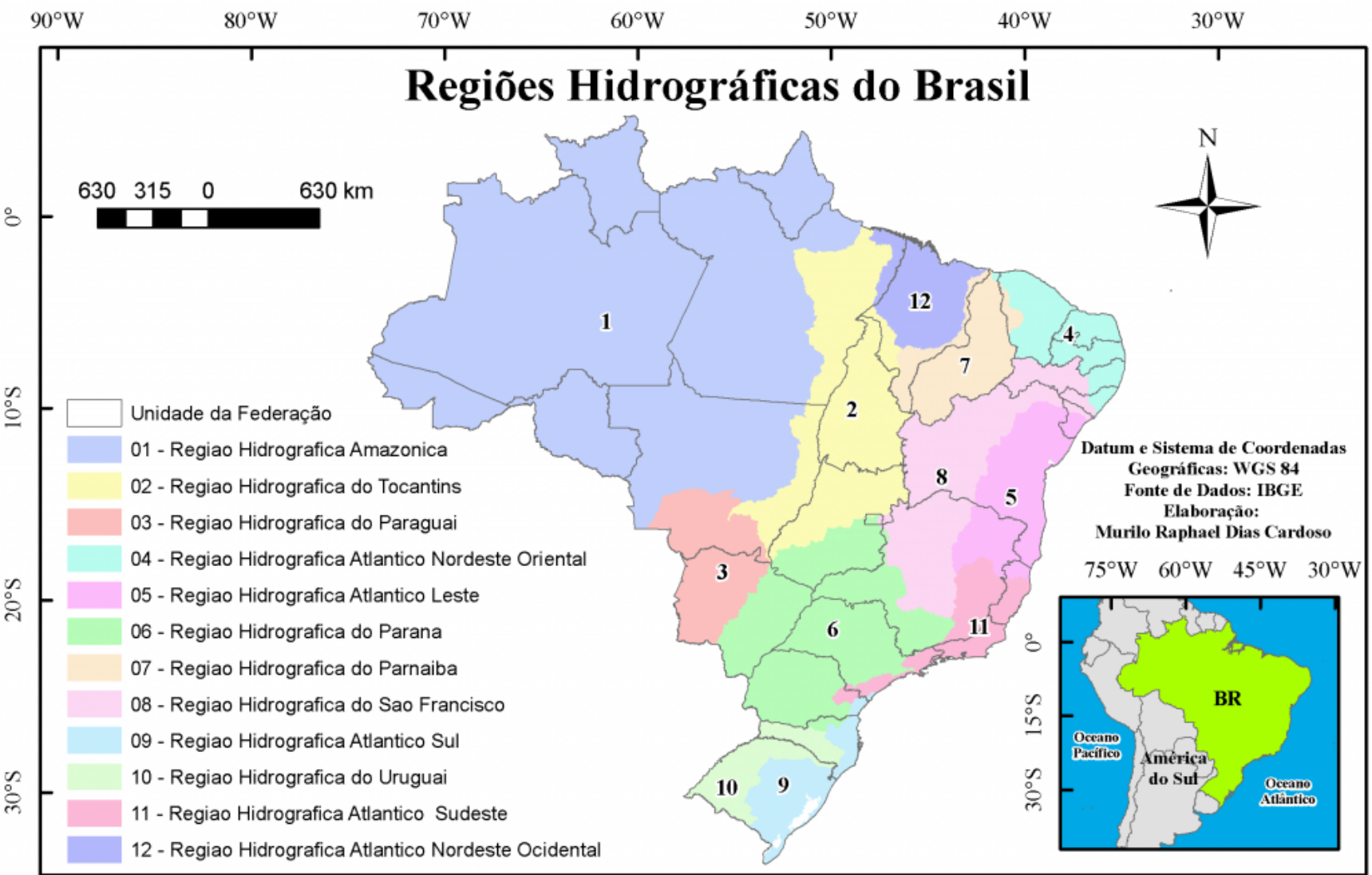

Figura 1: Regiões Hidrográficas do Brasil (CARDOSO, 2012).

Fonte: http://murilocardoso.com/2012/01/23/mapas-regioes-hidrograficas-bacias-hidrograficas-e-sub-bacias-dobrasil/ (Acesso em: jun, 2016).

No Estado do Rio de Janeiro, a Lei n 3.239/1999 estabeleceu a Política Estadual de Recursos Hídricos, cujos objetivos são dirimir eventuais conflitos relativos ao uso da água; acompanhar a Política Estadual de Recursos Hídricos; propor valores e aprovar critérios de cobrança pelo uso da água; assim como planejar, regular e controlar o uso, a preservação e a recuperação dos Recursos Hídricos.

Desde 2006, para viabilizar a implementação dos instrumentos relativos à cobrança pelo uso da água e otimizar a aplicação dos recursos financeiros arrecadados, o território estadual foi dividido em 10 Regiões Hidrográficas (RHs), segundo afinidades geopolíticas e ambientais, no entanto, em 2013 de acordo com a Resolução CERHI-RJ n 107/2013 as 10 RHs foram reduzidas para 9 visando a otimização do gerenciamento conforme observado na Figura 2; a área de atuação dos CBHs deve coincidir com a área da respectiva Região Hidrográfica. Atualmente, existem nove Comitês, que estão em diferentes fases de definição de seus instrumentos de gestão. 


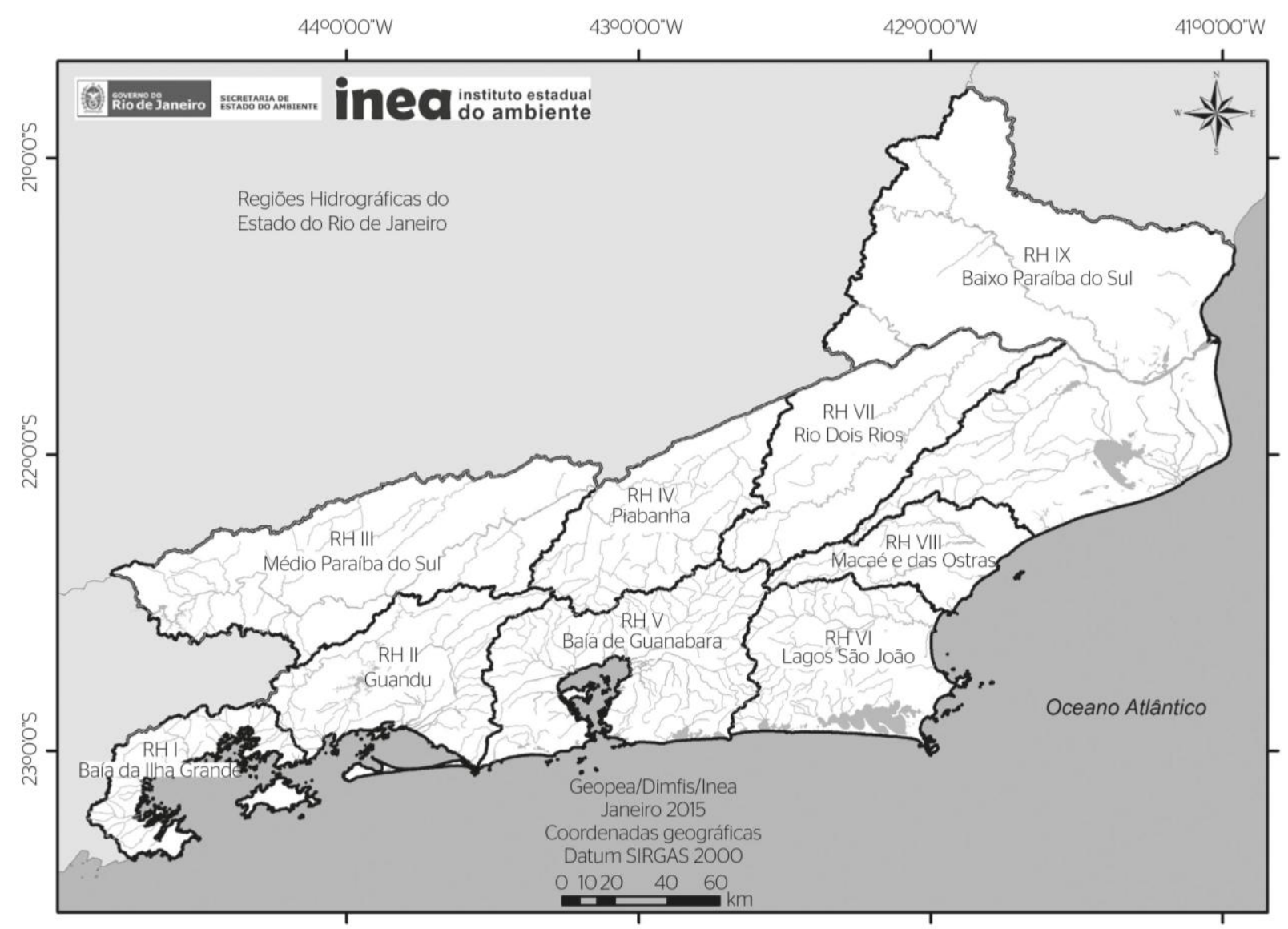

Figura 2: Regiões Hidrográficas do Estado do Rio de Janeiro (GEOPEAD/DIMFIS/INEA,2015 apud ACSELRAD, 2015). Fonte: http://www.scielo.br/scielo.php?script=sci_arttext\&pid=S1413-41522015000200199 (Acesso em: jun, 2016).

Ademais, podemos dizer que a Outorga como Gestão de Recurso Hídrico é um Instrumento importantíssimo que precede o Licenciamento Ambiental como é possível observar na Resolução CONAMA n ${ }^{\circ} 237 / 97$, em seu artigo $10^{\circ}, \S 1$. O referido trecho será abordado ao longo do presente artigo objetivando apresentar os critérios para deferimento do procedimento Licenciamento assim como sua respectiva emissão da Licença Ambiental a condicionante de possuir, quando for o caso, Outorga emitida pelo órgão competente.

\section{OBJETIVOS}

\subsection{Geral}

Apresentar o panorama da Gestão de Recursos Hídricos com foco no Estado do Rio de Janeiro.

\subsection{Específico}

Correlacionar a Gestão de Recursos Hídricos com o Licenciamento Ambiental;

Fomentar a Outorga de Direito de Uso como Instrumento decisivo no Licenciamento Ambiental. 


\section{METODOLOGIA}

O presente levantamento buscou relacionar os dados da literatura com a legislação vigente visando identificar avanços na Gestão de Recursos Hídricos como Instrumento decisivo para o Licenciamento Ambiental no Estado do Rio de Janeiro por meio de pesquisa nos sites do INEA, CONAMA, Comitês de Bacia entre outros. Além de pesquisa de imagens para ilustrar a divisão das Regiões Hidrográficas e tabelas para demonstração dos valores cobrados pelo uso da Água, em especial no Rio de Janeiro visando apresentar o panorama atual acerca da temática.

\section{APORTE TEÓRICO}

O Brasil possui um vasto arcabouço de leis relativo à gestão de Recursos Hídricos assim como o Estado do Rio de Janeiro. Para se ter uma ideia do assunto, a Lei de Direito da Água do Brasil é o Código das Águas, de 10 de julho de 1934, que, apesar de seus 82 anos, ainda é considerada pela doutrina jurídica, como um dos textos modelares do Direito Positivo brasileiro.

De acordo com COSTA (2010) a Constituição Brasileira, em vigência desde 1988, modificou, em vários aspectos, texto do Código de Águas. Uma das alterações feitas foi a extinção do domínio privado da água, previsto em alguns casos naquele antigo diploma legal. Todos os corpos d'água, a partir de outubro de 1988, passaram a ser de domínio público.

Ainda, o autor ressalta que uma outra modificação introduzida pela Constituição foi o estabelecimento de apenas dois domínios para os corpos d'água no Brasil:

a) o domínio da União, para os rios ou lagos que banhem mais de uma unidade federada, ou que sirvam de fronteira entre essas unidades, ou de fronteira entre o território do Brasil e o de um país vizinho ou dele provenham ou para ele se estendam; Como exemplo: O rio Paraíba do Sul que é de domínio da União porque banha mais de um Estado.

b) o domínio dos Estados, para as águas superficiais ou subterrâneas, fluentes, emergentes e em depósito, ressalvadas, neste caso, as decorrentes de obras da União. Como exemplo: O rio Piabanha é de domínio estadual, porque tem todo o seu curso inserido no Estado do Rio de Janeiro.

Ainda é importante citar que as águas subterrâneas, a Constituição definiu que elas são de domínio dos Estados.

Em 8 de janeiro de 1997, foi sancionada a Lei $n^{\circ} 9.433$ (a chamada Lei da Águas, que teve o exemplo francês, como inspiração), que organiza o setor de planejamento da gestão de Recursos Hídricos em âmbito nacional, introduzindo vários instrumentos de política para o setor. Vários Estados, tendo em vista o fato de serem detentores de um domínio sobre as águas, aprovaram suas 
respectivas leis de organização administrativa para o setor de Recursos Hídricos e, hoje, alguns deles encontram-se em avançado estado de regulamentação.

Desta forma, segue abaixo as Leis Federais, Estaduais e Portarias mais importantes no âmbito dos Recursos Hídricos.

\subsection{Legislação (Base Legal)}

\subsubsection{Federal}

CONSTITUIÇÃO FEDERAL - 1988

A partir da nova redação da Carta Magna em 1988 extinguiu-se o domínio particular da água que havia na Constituição de 1934. Todas as águas se tornaram de domínio público com competência da União, Estados e Distrito Federal para outorgar. Como observado em seu:

Art. 20 - São bens da União - os lagos, rios e quaisquer correntes de água em terrenos de seu domínio, ou que banhem mais de um Estado, sirvam de limites com outros países, ou se estendam a território estrangeiro ou dele provenham, bem como os terrenos marginais e as praias fluviais;

Art. 21 - Compete à União - instituir sistema nacional de gerenciamento de Recursos Hídricos e definir critérios de outorga de direitos de seu uso.

Art. 26 - Incluem-se entre os bens dos Estados - As águas superficiais ou subterrâneas, fluentes, emergentes e em depósito, ressalvadas, neste caso, na forma da lei, as decorrentes de obras da União.

\section{DECRETO FEDERAL Nº 24.643/1934 - CÓDIGO DAS ÁGUAS}

Mesmo com mais de oitenta anos, é considerado por muitos como a verdadeira Lei de Direito da Água no Brasil, tendo fortes influências em códigos ou leis mais atuais, como a Constituição Federal de 1988, a Lei n ${ }^{\circ}$ 9.433/97 e as legislações que tratam de Recursos Hídricos no Estado do Rio de Janeiro. Considere:

Art. $8^{\circ}$ - São particulares as nascentes e todas as águas situadas em terrenos que também o sejam, quando as mesmas não estiverem classificadas entre as águas comuns de todos, as águas públicas ou as águas comuns.

Art. 62 - As concessões ou autorizações para derivação que não se destine a produção de energia hidroelétrica serão outorgadas pela União pelos Estados ou pelos municípios.

\section{LEI FEDERAL N 9.433/1997 - POLÍTICA NACIONAL DE RECURSOS HÍDRICOS}

São aspectos relevantes da Lei $\mathrm{n}^{\circ} 9.433$ o estabelecimento de cinco instrumentos de política para o setor descritos a seguir:

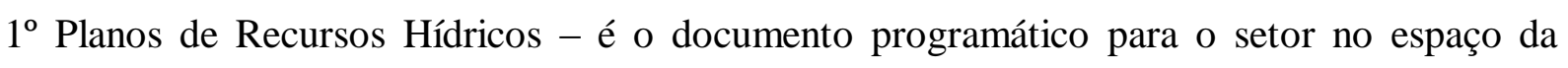
bacia. Trata-se de um trabalho de profundidade, não só de atualização das informações regionais que 
influenciam a tomada de decisão na região da bacia hidrográfica, mas que também procura definir, com clareza, a repartição das vazões entre os usuários interessados;

$2^{\circ}$ Enquadramento dos corpos d'água em classes de usos preponderantes - é importante para estabelecer um sistema de vigilância sobre os níveis de qualidade da água dos mananciais. Aliado a isso, trata-se de um instrumento que permite fazer a ligação entre a gestão da quantidade e a gestão da qualidade da água, isto é, fortalece a relação entre a gestão de Recursos Hídricos e a gestão do meio ambiente, tomando por base a Resolução ${ }^{\circ}$ 20/86, do CONAMA;

$3^{\text {o }}$ Outorga de Direito de Uso dos Recursos Hídricos - é o mecanismo pelo qual o usuário recebe uma autorização, ou uma concessão, para fazer uso da água. A outorga de direito, com a cobrança pelo uso da água, constitui relevante elemento para o controle e a disciplina do uso dos Recursos Hídricos;

Além disso, é válido, também, salientar que a Outorga está prevista na SEÇÃO III (Art.11 a 18).

$4^{\circ}$ Cobrança pelo uso da água - essencial para criar as condições de equilíbrio entre as forças da oferta (disponibilidade de água) e da demanda, promovendo, consequentemente, a harmonia entre os usuários competidores, ao mesmo tempo em que promove a redistribuição dos custos sociais, a melhoria da qualidade dos efluentes lançados, além de ensejar a formação de fundos financeiros para o setor;

$5^{\circ}$ Sistema Nacional de Informações sobre Recursos Hídricos - é destinado a coletar, organizar, criticar e difundir a base de dados relativa aos Recursos Hídricos, seus usos, o balanço hídrico de cada manancial e de cada bacia, provendo os gestores, os usuários, a sociedade civil e os outros segmentos interessados de condições necessárias para opinar no processo decisório ou mesmo para tomar suas decisões.

$\mathrm{Na}$ Lei também foi estabelecido um arranjo institucional, com base nos novos tipos de organização para a gestão compartilhada do uso da água. Esses novos organismos são: o Conselho Nacional de Recursos Hídricos, os comitês de bacias hidrográficas, as agências de água, além de órgãos e entidades dos serviços públicos federal, estadual e municipal, que têm relevante atuação na gestão dos Recursos Hídricos, devendo atuar em estreita parceria com os demais agentes previstos.

CONAMA RESOLUÇÃO Nº 357, 17/03/2005

Esta resolução do Conselho Nacional do Meio Ambiente dispõe sobre a classificação dos corpos de água e diretrizes ambientais para o seu enquadramento, bem como estabelece as condições e padrões de lançamento de efluentes, e dá outras providências. 
CONAMA RESOLUÇÃO Nº 396, 03/04/2008

Esta resolução do Conselho Nacional do Meio Ambiente dispõe sobre a classificação e diretrizes ambientais o enquadramento das águas subterrâneas, e dá outras providências.

CONAMA RESOLUÇÃO N 430, 13/05/2011

Esta resolução do Conselho Nacional do Meio Ambiente dispõe sobre as condições e padrões de lançamento de efluentes, complementa e altera a Resolução no 357, de 17 de março de 2005, do Conselho Nacional do Meio Ambiente - CONAMA.

CONAMA RESOLUÇÃO N 454, 01/11/2012

Esta resolução do Conselho Nacional do Meio Ambiente estabelece as diretrizes gerais e os procedimentos referenciais para o gerenciamento do material a ser dragado em águas sob jurisdição nacional.

\section{CONAMA RESOLUÇÃO Nº 237, 19/12/1997}

Estabelece critérios para exercício da competência para o Licenciamento Ambiental a que se refere o artigo 10 da Lei ${ }^{\circ}$ 6.938, de 31 de agosto de 1981 e as necessidades de integrar a atuação dos órgãos competentes do Sistema Nacional de Meio Ambiente - SISNAMA na execução da Política Nacional do Meio Ambiente, em conformidade com as respectivas competências.

Art. 10 - O procedimento de licenciamento ambiental obedecerá às seguintes etapas:

$\S 1^{\circ}$ - No procedimento de licenciamento ambiental deverá constar, obrigatoriamente, a certidão da Prefeitura Municipal, declarando que o local e o tipo de empreendimento ou atividade estão em conformidade com a legislação aplicável ao uso e ocupação do solo e, quando for o caso, a autorização para supressão de vegetação e a outorga para o uso da água, emitidas pelos órgãos competentes (grifo nosso).

\subsubsection{Estadual}

\section{LEI ESTADUAL Nº 3.239/1999 - POLÍTICA ESTADUAL DE RECURSOS HÍDRICOS}

Institui os Fundamentos e Instrumentos da Política Estadual de Recursos Hídricos; Cria o Sistema Estadual de Gerenciamento de Recursos Hídricos (Estrutura e Integrantes); Além de contemplar a Outorga - prevista na SEÇÃO V (Art.18 a 26).

LEI ESTADUAL $\mathrm{N}^{\circ} 4.247 / 2003$ - LEI DE COBRANÇA PELO USO DE RECURSO HÍDRICO

Dispõe sobre a cobrança pela utilização dos Recursos Hídricos de domínio do Estado do Rio de Janeiro e modifica alguns artigos da Lei ${ }^{\circ}$ 3.239/1999. E, logo em seguida, a Lei n 4.247/2003 é alterada pela $n^{\circ} 5.234 / 2008$. 
Art. $3^{\circ}$ - A cobrança pelos usos de Recursos Hídricos, sob a supervisão da Secretaria Estadual de Meio Ambiente, de que trata esta Lei, compete à Fundação Superintendência Estadual de Rios e Lagoas - SERLA, como o órgão responsável pela gestão e execução da política estadual de Recursos Hídricos, para arrecadar, distribuir e aplicar receitas oriundas da cobrança, segundo o plano de incentivos e aplicação de receitas definidos pelos comitês das respectivas bacias hidrográficas, onde estiverem organizados, em articulação com as prioridades apontadas pelo Plano de Bacia Hidrográfica.

\section{DECRETO ESTADUAL No $35.724 / 2004$}

Dispõe sobre a regulamentação do art.47 da Lei $\mathrm{n}^{\circ}$ 3.239, de 02 de agosto de 1999, que autoriza o poder executivo a instituir o fundo estadual de Recursos Hídricos - FUNDRIH, e dá outras providências

\section{DECRETO ESTADUAL No 40.156/2006}

Estabelece os procedimentos técnicos e administrativos para a regularização dos usos de água superficial e subterrânea, bem como, para ação integrada de fiscalização com os prestadores de serviço de saneamento básico, e dá outras providências. Observando:

Art. 10 - As águas superficiais ou subterrâneas, de domínio estadual, utilizadas como soluções alternativas de abastecimento, situadas em áreas abrangidas por serviço de abastecimento público, não poderão ser misturadas com a água, cuja competência de distribuição é deste último.

Art. 11 - A eficácia das outorgas para abastecimento residencial e comercial em áreas que contem com serviço de abastecimento público, ficará condicionada ao atendimento das seguintes exigências:

IV - proibição de utilização da água provida pelo sistema alternativo para consumo e higiene humana;

Usos Permitidos: \begin{tabular}{|c|c|c|c|c|}
\hline $\begin{array}{c}\text { Rega de jardins } \\
\text { e pátios }\end{array}$ & $\begin{array}{c}\text { Lavagem de } \\
\text { veículos }\end{array}$ & $\begin{array}{c}\text { Máquinas de } \\
\text { lavar roupa }\end{array}$ & Sanitários & Piscinas \\
\hline$\underline{\text { Usos Proibidos: }}$ & \begin{tabular}{|c|c|c|c|} 
Dessedentação \\
humana
\end{tabular} & $\begin{array}{c}\text { Preparação de } \\
\text { alimentos }\end{array}$ & Banho & Pias em geral \\
\hline
\end{tabular}

V - proibição de utilização de água provida pelo sistema alternativo para comercialização;

VI - pagamento, ao responsável pelo serviço público de esgotamento sanitário, do valor correspondente ao lançamento de efluentes na rede, calculado com base nos volumes de captação hidrometrados referidos no inciso I deste artigo e nas tarifas de esgoto atribuídas pelo responsável pelo serviço. 
Art. 12 - Nas outorgas de uso da água para abastecimento industrial, em áreas que contem com sistema de abastecimento público, o atendimento às exigências expressas nos incisos III e IV do art. 11 deste Decreto poderá ser dispensado a critério da SERLA.

\begin{tabular}{|c|c|c|c|c|}
\hline$\frac{\text { Usos Industriais }}{\text { Permitidos: }}$ & $\begin{array}{l}\text { Indústria de } \\
\text { alimentos }\end{array}$ & Indústria de bebidas & $\begin{array}{l}\text { Indústria de } \\
\text { remédios }\end{array}$ & $\begin{array}{c}\text { produtos } \\
\text { farmacêuticos }\end{array}$ \\
\hline
\end{tabular}

Parágrafo único - A mistura das águas oriundas do sistema alternativo com águas oriundas do sistema público deverá ser precedida de um dispositivo onde, inequivocamente, seja conhecida a separação desses dois sistemas, eliminando-se os riscos de o sistema alternativo alcançar pontos anteriores ao dispositivo de separação.

\section{LEI ESTADUAL N 5.101/2007 - CRIAÇÃO DO INEA}

Dispõe sobre a criação do Instituto Estadual do Ambiente - INEA para maior eficiência na execução das políticas estaduais de meio ambiente, de Recursos Hídricos e florestais. Destacando:

Art. $3^{\circ}$ - A instalação do Instituto implicará na extinção da Fundação Estadual de Engenharia do Meio Ambiente - FEEMA, da Fundação Superintendência Estadual de Rios e Lagoas - SERLA, da Fundação Instituto Estadual de Florestas - IEF, com a consequente transferência de suas competências e atribuições.

É importante evidenciar que a implementação ocorreu apenas em 12/01/2009 considerando o Decreto $\mathrm{n}^{\circ} 41.628 / 09$, porque por meio dele estabelecia-se a estrutura organizacional do novo órgão, o INEA.

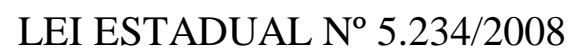

Altera a Lei $\mathrm{n}^{\circ} 4.247$, de 16 de dezembro de 2003, que dispõe sobre a cobrança pela utilização dos Recursos Hídricos de domínio do Estado do Rio de Janeiro.

\section{PORTARIA SERLA No 555/2007}

Regulamenta o Decreto Estadual no 40.156, de 17 de Outubro de 2006, que estabelece os procedimentos técnicos e administrativos para regularização dos usos de água superficial e subterrânea pelas soluções alternativas de abastecimento de água e para a ação integrada de fiscalização com os prestadores de serviços de saneamento.

\section{PORTARIA SERLA N 564/2007}

Define procedimentos para pagamento referente à Cobrança pelo Uso de Recursos Hídricos de domínio do Estado do Rio de Janeiro.

\section{PORTARIA SERLA N ${ }^{\circ} 567 / 2007$}

Visa estabelecer os procedimentos técnicos e administrativos para fins de outorga de direito de uso dos Recursos Hídricos, bem como a sua renovação, alteração, transferência, desistência, 
suspensão e revogação em corpos d'água sob domínio do Estado do Rio de Janeiro, nos termos da legislação pertinente.

\section{RESOLUÇÃO INEA Nº 63/2012}

Aprova a normatização e os procedimentos para abertura de processos, análise e emissão de Certidão Ambiental de uso insignificante de Recursos Hídricos.

RESOLUÇÃO INEA Nº 77/2013

Aprova a normatização que estabelece os critérios e procedimentos para concessão de autorização ambiental para perfuração de poços tubulares para uso do Recurso Hídrico subterrâneo.

RESOLUÇÃO INEA No 84/2014

Aprova os critérios que estabelecem a concessão de inexigibilidade de documentos de uso insignificante de Recursos Hídricos.

\section{NORMA INSTITUCIONAL INEA No 04/2013}

Regularização de Recursos Hídricos para todas as finalidades de uso através de veículo transportador (carro -pipa).

\subsection{Outorga}

Destarte, considerando a legislação apresentada anteriormente é fundamental para a otimização da Gestão do Recurso Hídrico a definição de alguns conceitos e procedimentos e pensando nesta crescente demanda serão apresentados os principais itens que norteiam os requerimentos.

\subsubsection{O Que é Outorga?}

É o ato administrativo mediante o qual o poder público outorgante (União, Estado ou Distrito Federal) faculta ao outorgado (requerente) o direito de uso de Recurso Hídrico, por prazo determinado, nos termos e nas condições expressas no respectivo ato administrativo (ANA, s.d.). A outorga do direito de uso dos Recursos Hídricos é um dos instrumentos de Gestão Recursos Hídricos, previsto na Lei $\mathrm{n}^{\circ} 3.239 / 99$ e tem como principal objetivo gerenciar o controle qualiquantitativo dos usos da água e o efetivo exercício dos direitos de acesso a ela. No Estado do Rio de Janeiro o ato normativo utilizado para emissão das outorgas denomina-se "Ato de Outorga". Cabe à Diretoria de Licenciamento Ambiental do INEA a edição do Ato de Outorga cujo extrato é publicado no Diário Oficial do Estado do Rio de Janeiro.

\subsubsection{Por que Outorgar?}

Para garantir a todos os usuários o acesso à água, visando o uso múltiplo e a preservação das espécies da fauna e flora endêmicas ou em perigo de extinção (Art.19, Lei no 3239/99). Desta forma, 
visa minimizar os conflitos entre os diversos setores usuários e evitar impactos ambientais negativos aos corpos hídricos.

\subsubsection{Características da Outorga}

Algumas características da outorga são fundamentais para regular o uso do recurso hídrico, em função disso, no documento deverão constar as principais informações que irão orientar o requerente, bem como:

Só o autorizado possui obrigações

Prazo variável, não excedendo 35 anos, renovável

O direito de uso é inalienável (não pode vender)

Pode transferir para outro desde que seja exatamente nas mesmas condições da outorga original

Se o novo usuário quiser fazer alguma alteração, deverá solicitá-la por averbação

Está sujeita à fiscalização e à cobrança pelo uso de Recursos Hídricos

Ademais, existem condicionantes de diversas naturezas, tais como:

Condições gerais:

A outorga está condicionada às prioridades de uso estabelecidas nos Planos de RH

A outorga deve respeitar a classe em que o corpo de água estiver enquadrado

A outorga deve respeitar a manutenção das condições adequadas ao transporte aquaviário

A outorga deve preservar o uso múltiplo de Recursos Hídricos

Condições de suspensão e revogação:

Não cumprimento dos termos da outorga

Ausência de uso por três anos

Necessidade premente de água para atender a situações de calamidade

Necessidade de se prevenir ou reverter degradação ambiental

Necessidade de se atender a usos prioritários, de interesse coletivo, para os quais não se disponha de fontes alternativas

Necessidade de serem mantidas as características de navegabilidade

Indeferimento ou cassação da licença ambiental 


\subsubsection{Usos que DEPENDEM de Outorga}

O Art. 22 da Lei $n^{\text {o }} 3239 / 99$ determina que estão sujeitos à outorga os seguintes usos de Recursos Hídricos:

\begin{tabular}{|c|l|}
\hline I & $\begin{array}{l}\text { derivação ou captação de parcela da água existente em um corpo de } \\
\text { água, para consumo }\end{array}$ \\
\hline II & extração de água de aquífero \\
\hline III & $\begin{array}{l}\text { lançamento, em corpo de água, de esgotos e demais resíduos } \\
\text { lídos ou gasosos, tratados ou não, com o fim de sua diluição, } \\
\text { transporte ou disposição final }\end{array}$ \\
\hline IV & aproveitamento dos potenciais hidrelétricos \\
\hline V & $\begin{array}{l}\text { outros usos que alterem o regime, a quantidade ou a qualidade da } \\
\text { água existente em um corpo hídrico }\end{array}$ \\
\hline
\end{tabular}

\subsubsection{Usos que INDEPENDEM de Outorga}

Segundo a Lei $\mathrm{n}^{\circ}$ 4.247/03 alterada pela Lei n ${ }^{\circ}$ 5.234/08: o uso de Recursos Hídricos para a satisfação das necessidades de pequenos núcleos populacionais, ou o de caráter individual, para atender às necessidades básicas da vida, distribuídos no meio rural ou urbano. Essa inexigibilidade foi fomentada posteriormente pela Resolução INEA n 84/14. Além disso são analisadas as derivações, captações, extrações, lançamentos e acumulações da água em volumes considerados insignificantes. Também devem ser observados os limites de uso considerados insignificantes tal como as extrações de água subterrânea inferiores ao volume diário equivalente a 5.000 (cinco mil) litros e respectivos efluentes (inserido pela Lei $n^{\circ}$ 5.234/08) e 34.560 (trinta e quatro mil quinhentos e sessenta) litros de água superficial.

\subsection{Cobrança pelo Uso da Água}

Bem como observado anteriormente a cobrança pelo uso da água é um dos instrumentos previstos na Lei das Águas ( $n^{\circ}$ 9.433/97), que instituiu a Política Nacional dos Recursos Hídricos e na Lei Estadual de Recursos Hídricos (nº 3.239/99). O objetivo deste instrumento é estimular o uso racional da água e gerar recursos financeiros para investimento na recuperação e preservação dos mananciais da área alvo.

Considerando relatos de COSTA (2010) a cobrança pelo uso da água no Estado do Rio de Janeiro teve início em 2004 sendo adotado como auto declaratório o Cadastro Nacional de Usuários de Recursos Hídricos - CNARH que é um banco de dados regulado e administrado pela Agência Nacional de Água - ANA. Sendo assim, o Estado do Rio de Janeiro é o único estado que não tem seu banco de dados próprio, alimentando um cadastro nacional. Os recursos financeiros arrecadados 
são recolhidos ao Fundo Estaduais de Recursos Hídricos (FUNDRHI), sendo administrado pelo INEA.

Inclusive, o autor reforça que do montante arrecadado com a cobrança pelo uso da água, $10 \%$ devem ser aplicados no órgão gestor (INEA) e os restantes $90 \%$ na região onde foram arrecadados, com base nos programas previstos no Plano de Bacias aprovado pelo respectivo Comitê. O Plano contém um programa de ações e investimentos para recuperação e preservação dos Recursos Hídricos. Onde não existe comitê, o recurso é aplicado na região diretamente pelo INEA com a concordância do Conselho Estadual de Recursos Hídricos (CERHI).

É importante ressaltar, porém, que os valores disponíveis para aplicação não são exatamente iguais àqueles valores arrecadados na respectiva região hidrográfica, uma vez que há dedução de taxas bancárias e, no caso do rio Guandú localizada na RH II e do trecho do Rio Paraíba do Sul localizado na RH III, há a obrigatoriedade de $15 \%$ dos valores arrecadados no Guandu serem aplicados no Paraíba do Sul, em virtude da transposição para abastecimento da Região Metropolitana do Rio de Janeiro (COSTA, 2010).

A cobrança aplica-se à captação de água bruta, consumo e lançamento de efluentes nos corpos hídricos, de acordo com os usos declarados e consolidados, como observado na Tabela 1.

Tabela 1: Valores de cobrança pelo uso da água (INEA, s.d).

\begin{tabular}{|c|c|c|c|c|}
\hline \multirow[b]{2}{*}{ Setor } & \multirow{2}{*}{$\begin{array}{c}\text { PPU } \\
\left(\mathrm{RS} / \mathrm{m}^{3}\right)\end{array}$} & \multirow[b]{2}{*}{ Outros Critérios } & \multicolumn{2}{|c|}{ Uso Insignificante } \\
\hline & & & $\begin{array}{c}\text { Água } \\
\text { subterränea }\end{array}$ & $\begin{array}{l}\text { Água } \\
\text { superficial }\end{array}$ \\
\hline $\begin{array}{l}\text { Saneamento e } \\
\text { Indústria }\end{array}$ & 0,02 & - & $5.000 \mathrm{~L} / \mathrm{dia}$ & \multirow{3}{*}{$\begin{array}{c}0,4 \mathrm{~L} / \mathrm{s} \text { ou } \\
34.560 \mathrm{~L} / \mathrm{dia}\end{array}$} \\
\hline Agropecuária & 0,0005 & $\begin{array}{l}\mathrm{DBO}=0 \text {, exceto } \\
\text { suinocultura } \\
\text { (*) Impacto }<0,5 \% \\
\text { custo produção }\end{array}$ & \multirow{2}{*}{$\begin{array}{c}0,4 \mathrm{~L} / \mathrm{s} \text { ou } \\
34.560 \mathrm{~L} / \mathrm{dla}\end{array}$} & \\
\hline Aquicultura & 0,0004 & $\begin{array}{c}\text { Consumo e DBO }=0 \\
\left({ }^{*}\right) \text { impacto }<0,5 \% \\
\text { custo produçăo }\end{array}$ & & \\
\hline PCHs & - & $\begin{array}{c}0,75 \% \times \text { Energia Gerada } \\
\text { x TAR }\end{array}$ & \multicolumn{2}{|c|}{$1 \mathrm{MW}$} \\
\hline
\end{tabular}

Fonte: http://www.inea.rj.gov.br/Portal/MegaDropDown/Institucional/GestaoParticipativa/ Cobrancapelousodaagua/index.htm\&lang= (Acesso em: jun, 2016).

É importante ressaltar que os chamados Usos Insignificantes para água subterrânea (referente ao consumo de até 5.000L/dia, apresentado na tabela acima) não estão sujeitos à outorga e à cobrança, porém devem ser cadastrados e obter a devida autorização de uso junto ao INEA. Além disso, estão sujeitos à fiscalização realizada pelo órgão ambiental e, em caso de inconsistência os dados, o usuário poderá sofrer sanções previstas em lei. 


\section{CONSIDERAÇÕES FINAIS}

Como observado a Outorga de Direito de Uso de Recurso Hídrico é um Instrumento fundamental que precede o Licenciamento Ambiental, em especial no Estado do Rio de Janeiro por meio da fusão de 3 extintos órgãos ambientais que originaram em 2007, porém sendo efetivado apenas em 2009, o INEA, objeto de estudo do presente trabalho. Entende-se como Outorga um ato administrativo que o outorgante (União, Estado ou Distrito Federal) faculta ao outorgado (requerente) o direito de uso de Recurso Hídrico estabelecendo condicionantes e os devidos prazos de acordo os usos previstos nos requerimentos; além de ser imperativo o cadastro no Sistema OnLine. A Legislação Federal e Estadual vigente dispõe garantias a todos os usuários o acesso à água, tendo em vista o uso múltiplo e a preservação das espécies da fauna e flora endêmicas ou em perigo de extinção (Art.19, Lei $\mathrm{n}^{\mathrm{o}}$ 3239/99) tornando fator decisivo ao combate dos conflitos entre os diferentes setores usuários e visando evitar impactos ambientais negativos sobretudo aos corpos hídricos. Em especial, CONAMA no 237/97 diz que a Obtenção da Outorga precede o Licenciamento Ambiental sendo um dos critérios para deferimento para emissão da Licença. Sendo assim, o presente artigo teve o compromisso de apresentar o panorama da Gestão de Recursos Hídricos com foco no Estado do Rio de Janeiro tendo como objetivo específico correlacionar a Gestão de Recursos Hídricos com o Licenciamento Ambiental além de fomentar a Outorga de Direito de Uso como instrumento decisivo no Licenciamento Ambiental usando como base o levantamento de dados da literatura e da legislação atualizada visando identificar avanços na Gestão de Recursos Hídricos e do Licenciamento Ambiental no Estado do Rio de Janeiro.

\section{REFERENCIA BIBLIOGRÁFICA}

1. ACSELRAD, M. V.; AZEVEDO, J. P. S. de; FORMIGA-JOHNSSON, R. M. Cobrança pelo uso da água no Estado do Rio de Janeiro, Brasil (2004-2013): histórico e desafios atuais. Eng. Sanit. Ambient, Rio de Janeiro, v. 20, n. 2, p. 199-208, jun. 2015. Disponível em: <http://www.scielo.br/scielo.php?script=sci_arttext\&pid=S1413-41522015000200199> Acesso em: 15/06/16;

2. Agência Nacional de Águas - ANA. Outorga. ANA, s.d. Disponível em: <http://www2.ana. gov.br/Paginas/institucional/SobreaAna/uorgs/sof/geout.aspx> Acesso em: 14/06/16;

3. CARDOSO, M. [Mapas] Regiões Hidrográficas, Bacias Hidrográficas e Sub-bacias do Brasil. 2012. Disponível em: <http://murilocardoso.com/2012/01/23/mapas-regioeshidrograficas-bacias-hidrograficas-e-sub-bacias-do-brasil/> Acesso em: 15/06/16; 
4. COSTA, M. T. A Outorga de Uso na Gestão dos Recursos Hídricos Subterrâneos do Estado do Rio de Janeiro. Rio de Janeiro: UVA. 2010. 55p;

5. FUNDAÇÃO COPPETC/Laboratório de Hidrologia e Estudos de Meio Ambiente. Elaboração do Plano Estadual de Recursos Hídricos do Estado do Rio de Janeiro: R7 Relatório Diagnóstico (versão final) Rio de Janeiro: INEA/SEA, mar. 2014. Disponível em: <http://www.inea.rj.gov.br/cs/groups/public/documents/document/zwew/mdyy/ edisp/inea00 62195.pdf> Acesso em: 14/06/16;

6. GEOPEAD/DIMFIS/INEA, 2015 apud ACSELRAD, M. V.; AZEVEDO, J. P. S. de; FORMIGA-JOHNSSON, R. M. Cobrança pelo uso da água no Estado do Rio de Janeiro, Brasil (2004-2013): histórico e desafios atuais. Eng. Sanit. Ambient, Rio de Janeiro, v. 20, n. 2, p. 199-208, jun. 2015. Disponível em: <http://www.scielo.br/scielo.php?script= sci_arttext\&pid=S1413-41522015000200199> Acesso em: 15/06/16;

7. Instituto Estadual do Ambiente - INEA. Cobrança pelo Uso de Recursos Hídricos. Instituto Estadual do Ambiente - INEA, s.d.. Disponível em: <http://www.inea.rj.gov.br/Portal/ MegaDropDown/Institucional/GestaoParticipativa/Cobrancapelousodaagua/index.htm\&lang=> Acesso em: 15/06/16;

8. As Legislações Estaduais foram consultadas no site, disponível em: <http://www.inea.rj.gov.br/Portal/MegaDropDown/Legislacao/index.htm> Acesso em: 15/06/16;

9. MANSUR, K. L.; MARTINS, A. M. O caso das Águas Subterrâneas no Estado do Rio de Janeiro. Disponível em: <https://aguassubterraneas.abas.org/asubterraneas/article/viewFile/ 23960/16013> Acesso em: 10/06/16;

10. Ministério do Meio Ambiente - MMA. As Legislações Federais foram consultadas no site, disponível em: <http://www.mma.gov.br/port/conama/> Acesso em: 15/06/16;

11. NUNES, T. C. de O.; RAMOS, M. de O. Licenciamento Ambiental no Estado do Rio de Janeiro: Simplificação e Aprimoramento da Regularização do Uso da Água. Revista ADM.MADE, ano 10, v.14, n.3, p.82-94, out/dez, 2010. Rio de Janeiro. ISSN: 1518-9929. Disponível em: <http://revistaadmmade.estacio.br/index.php/admmade/article/viewFile/ 106/100> Acesso em: 10/06/16;

12. Orientações para a obtenção de Outorga do Uso da Água. Rio de Janeiro: GMA, 2006. Sistema FIRJAM. 23p;

13. REGO, V. V. B. S. Reflexões sobre a política estadual de recursos hídricos do Rio de Janeiro a partir da implementação dos Comitês de Bacia Hidrográfica. In: Boletim do Observatório Ambiental Alberto Ribeiro Lamego, Campos dos Goytacazes/RJ, v.6 n.2, p. 135-152, jul/dez 
2012. Disponível em: <http://essentiaeditora.iff.edu.br/index.php/boletim/article/viewFile/ 21774560.20120019/2760> Acesso em: 10/06/16;

14. ROMANO, L. S. et al. Base Legal para a gestão das Águas no Estado do Rio de Janeiro (1997-2013) / Instituto Estadual do Ambiente - INEA - 2a ed. ver. e amp. - Rio de Janeiro, 2014. ISBN: 987-85-63884-17-6. 500p. il;

15. SILVA, L. M. C. da; MONTEIRO, R. A. Outorga de Direito de Uso de Recursos Hídricos: Uma das Possíveis Abordagens. Disponível em: <http://143.107.108.83/sigrh/cobranca/ pdf/leitura_04.pdf> Acesso em: 10/06/16. 